\title{
Regional Covid-19 Mortality in Brazil by Age
}

\author{
Emerson A. Baptista \\ Asian Demographic Research Institute \\ emersonaug@gmail.com \\ Bernardo Lanza Queiroz \\ Universidade Federal de Minas Gerais \\ lanza@cedeplar.ufmg.br
}

\begin{abstract}
In this study, we introduce a ternary colour coding to visualize and compare the age structure of deaths by COVID-19 (until 06/30/2020) in Brazilian small-areas using the tricolore package in R. The analysis of age profile is important to better understand the dynamics of the pandemic and how it affects the population according to age groups $(0-19,20-59$, and $>60$ years $)$ and regions of the country. The results highlight the importance of looking at the small-areas and show that there are many pandemics going on in Brazil at the same time, instead of a single one. The pandemic is increasing in the interior of the country, but we still observed several cases and deaths in the major cities and, as of today, very few signs of reduction in the spread of the disease. We also show that the number of cases is more concentrated in females, but deaths are prevalent among men. The CFR for males is greater than the ones for females, but also mortality for young adult males is greater when compared with other countries.
\end{abstract}




\section{Introduction}

The COVID-19 pandemic has negatively impacted public health worldwide. Recently, Latin America and Brazil have become the new epicenter of the disease (Anderson et al. 2020; Barreto et al. 2020; Rodriguez-Morales et al. 2020; The Lancet 2020). By not following WHO recommendations and ignoring effective measures that were implemented in most countries that successfully control the pandemic, Brazil is following a very bad path. Currently, the country is the second in number of confirmed cases and deaths, behind only the United States (Dong, Du and Gardner 2020). However, there are important regional disparities in the progress of the pandemic, which leads us to investigate and evaluate the spatial distribution of mortality by COVID-19, as well as to understand how the pandemic spread across regions in a less developed and younger population (Codeço et al. 2020; Souza et al. 2020).

COVID-19 deaths show a considerable gradient by age, very similar to that observed in the general mortality rates of a population (Goldstein and Lee 2020). Mortality rates are much higher for the elderly than for adults and the young, and in most countries, higher for males than for females. Therefore, population age structure is a risk factor for higher mortality, so that in locations with an older population a relatively higher overall number of deaths is expected (Dowd et al. 2020; Goldstein and Lee 2020). However, COVID-19 also appears to be more dangerous for people with previous health problems. Evidence shows that cardiovascular diseases, diabetes and obesity increase the risk of complications and deaths for infected people (Jordan et al. 2020; Nepomuceno et al. 2020; Shuchman 2020). In developing countries, therefore, the level of morbidity of the younger population may act as an additional risk for COVID-19. If, on the one hand, a younger age structure is a protective factor, general levels of morbidity may have the opposite effect (Nepomuceno et al. 2020; Shuchman 2020). These studies are important for understanding the different aspects of the spread of the pandemic at the national level. However, sub-national variations and differences should also be considered in the analysis to provide support for public health interventions.

In the first moments of the epidemic in Brazil, most deaths were concentrated in places where the first infections were registered (Souza et al. 2020). However, throughout the process of spreading and internalizing the pandemic, understanding the spatial pattern of mortality (Schmertmann and Gonzaga 2018; Baptista and Queiroz 2019) and of the age structure of the 
population (Dowd et al. 2020; Kashnitsky 2020) before the pandemic can help policymakers to respond to potential regional differentials of mortality due to diseases, as well as contribute to the understanding of possible differences in the age structure of mortality by COVID-19 (Barreto et al. 2020). In short, the risks of death in Brazil are largely related to the age structure of the population, general health conditions and socioeconomic situation to which the population is exposed (Borges 2017; França et al. 2017). Therefore, in a country marked by major regional and socioeconomic differences (Ribeiro and Leist 2020), which occur regardless of geographic level (Queiroz et al. 2017; Schmertmann and Gonzaga 2018; Baptista and Queiroz 2019), this analysis is essential. Additionally, there is an hypothesis that mortality by COVID-19 in Brazil has a younger age structure than observed in other countries (Guilmoto 2020) and this regional analysis might shed some light on this discussion.

In this study, we introduce a ternary colour coding to visualize and compare the age structure of deaths by COVID-19 (until 06/30/2020) in Brazilian small-areas using the tricolore package (Kashnitsky and Schöley 2018) in R. In addition, we calculate COVID-19 case fatality rates and mortality ratios. The analysis of age profile is important for better understanding the dynamics of the pandemic (Dudel n.d.; Guilmoto 2020) and how it affects the population according to age groups $(0-19,20-59$, and $>60$ years $)$ and regions of the country. In most countries, mortality is higher for older individuals (Goldstein and Lee 2020; Jin et al. 2020; Kang, undefined/ed), but recent research highlights the possibility of high mortality rates for younger ages in less developed economies. In the case of Brazil, one can add the large regional differences that may also play an important role in mortality risks (Nepomuceno et al. 2020; Rezende et al. 2020).

\section{Data and Methods}

\section{Data source and level of analysis}

We use the database of the Ministry of Health of Brazil, DATASUS, which is publicly available online (https://opendatasus.saude.gov.br/dataset/casos-nacionais). The Ministry of Health, through the Health Surveillance Secretariat (SVS), has been developing surveillance for Serious Acute Respiratory Syndrome (SARI) in Brazil since 2009, due to the Influenza A (H1N1) pandemic. Thereafter, SARS was incorporated into the surveillance network for Influenza and other respiratory viruses and, recently (2020), COVID-19, the human infection caused by the new 
Coronavirus that generated a global pandemic, also became part of the network. We collected the information on June $30^{\text {th }}$, when Brazil had registered 54.470 deaths and 1.113.682 cases.

The original data are available at the individual level (case by case) and by municipality. The main limitation in using city level data in Brazil is that the population sizes, as well as the number of cases and deaths, are very small in some localities, which can cause many random fluctuations. To avoid problems, but maintaining the importance of analyzing and understanding regional variations, we aggregated municipalities in 137 comparable small areas, using the IBGE definition of geographic meso-regions. These geographical areas are statistical constructions aggregated using regional and socioeconomic similarities and have not changed their boundaries over time. In addition, they have been used elsewhere (Lima and Queiroz 2014; Baptista and Queiroz 2020). We also produce estimates using standardized rates so that we can compare COVID-19 mortality levels, thereby eliminating effects of population age structure (Dowd et al. 2020).

\section{Ternary colour coding}

We used the approach proposed by Kashnitsky and Schöley (2018) to investigate the spatio-temporal variation of deaths by COVID-19 in Brazilian meso-regions. We map the age profile (0-19, 20-59, and >60 years) of COVID-19 deaths using ternary colour coding. This technique maximises the amount of information conveyed by colours. Each element of a threedimensional array of compositional data, in our case, three age groups, is represented with a unique colour. In other words, ternary colour coding is designed to visualize proportions of a whole, that is, anything that splits in three non-negative parts that add up to unity. This is perhaps its biggest limitation, and a second one occurs when there is unbalanced data. In this study, COVID-19 deaths are concentrated in adults and the elderly; that is, there is little variation with regards to the visual reference point, which is the greypoint that marks perfectly balanced proportions (Kashnitsky and Aburto 2019; Schöley 2019). Therefore, and to see the internal variation of the data, we have changed the point of reference to the location of the average Brazilian mortality structure of COVID-19, thereby visualizing direction and magnitude of the deviations from that average. 


\section{Results}

Figure 1 shows Case Fatality Rates (CFR) for males and females. CFR is the proportion of COVID-19 deaths by the total number of people diagnosed with the disease, by age, sex and in a specific period of time. It is important to stress that CFR for COVID-19 changes constantly and it is different over time and regions. Specifically, here, our goal is just to show the differences by age and sex in Brazil. CFR is not an appropriate measure of mortality risk by COVID-19, as it is affected by the number of people who receive the proper diagnostic. That is, in countries with very few tests we might observe very high CFR because only those in hospitals or severe symptoms are being tested. In addition, we are counting deaths at a specific point of time, but some people with the disease might have a positive or negative outcome. In the case of Brazil, we observed that CFRs for males are higher than for females in all age groups - as observed in other countries. However, CFRs for younger adults are greater than observed in other countries.

Figure 1. COVID-19 Case Fatality Rates (CFR), by age groups and sex, Brazil, 2020 (June, $\left.3^{\text {th }}\right)$

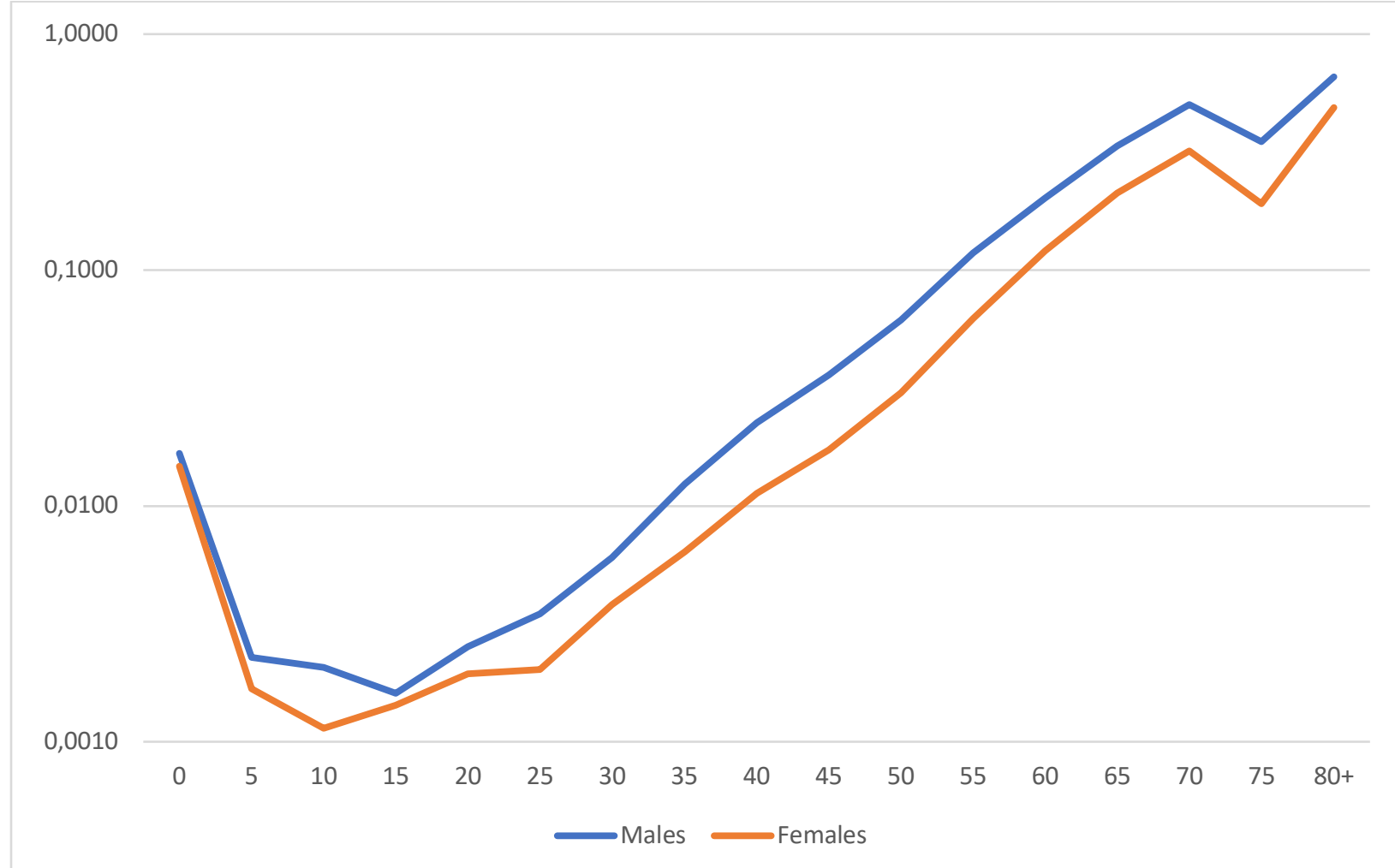


Table 1 shows summary results for the country and the main regions. The distribution of COVID-19 deaths by age in Brazil follows a very similar pattern than observed in other countries. For males, we find that $0.60 \%$ of deaths are for individuals younger than 19 years of age, $28.20 \%$ for those aged 20 to 59, and $71.20 \%$ for those aged 60 and above. For females, the values are $0.77 \%, 24.70 \%$ and $74.02 \%$, respectively. In addition, there is some variation across regions of the country that we will highlight later. The observed CFR for males is higher than for females for all age groups, and the difference increases for young adults and extends to older ages (Natale et al. 2020; Rezende et al. 2020).

There is also an interesting gender pattern. In the country, we observe the ratio male to female for deaths in around 1.44 , that is, there are 144 male deaths to 100 female deaths. The ratio ranges from 1.52 in the North to 1.29 in the Center-West. For confirmed cases in the country, we calculate a ratio of 0.88 , that is, 88 male cases for every 100 female cases.

Table 1. Summary statistics, COVID-19, Brazil and regions, 2020

\begin{tabular}{|l|c|c|c|c|c|c|}
\multicolumn{1}{|c|}{ Region } & $\begin{array}{c}\mathrm{M} / \mathrm{F} \\
\text { deaths }\end{array}$ & $\begin{array}{c}\mathrm{M} / \mathrm{F} \\
\text { cases }\end{array}$ & $\begin{array}{c}\text { CFR - } \\
\text { Females }\end{array}$ & $\begin{array}{c}\text { CFR - } \\
\text { Males }\end{array}$ & $\begin{array}{c}\text { \% deaths } \\
20-59\end{array}$ & $60+$ \\
\hline North & 1.52 & 0.76 & 0.0225 & 0.0435 & 24.40 & 74.74 \\
\hline Northeast & 1.44 & 0.86 & 0.0195 & 0.0327 & 27.07 & 71.49 \\
\hline Center-West & 1.29 & 0.98 & 0.0167 & 0.0219 & 31.02 & 67.34 \\
\hline Southeast & 1.33 & 0.98 & 0.0331 & 0.0446 & 31.28 & 68.06 \\
\hline South & 1.46 & 0.92 & 0.0145 & 0.0232 & 32.46 & 66.48 \\
\hline Brazil & 1.44 & 0.88 & 0.0218 & 0.0368 & 27.04 & 71.89 \\
\hline
\end{tabular}

Figure 2 shows, for males and females, the proportional distribution of COVID-19 deaths by age groups across Brazilian meso-regions. The overall results show that, for both sexes, the percentage of deaths in the older age group (above 60) is higher in 9 out of 10 meso-regions. When comparing men and women, in approximately $73 \%, 85 \%$ and $82 \%$ of meso-regions, the number of deaths of men is higher than that of women in the $0-19,20-59$, and 60 and above age groups, respectively. 
The figure also shows the Brazilian mortality by COVID-19 with the color scale altered so that the visual point of reference (point of intersection of the three lines within the triangle) is positioned at the Brazilian average. The colors present direction and magnitude of the deviation from the Brazilian average distribution of COVID-19 mortality by age groups. Yellow, green and pink show a higher than average share of COVID-19 deaths in the 0-19, 20-59 and 60+ age groups. The saturation of the colors exhibits the amplitude of that deviation with perfect grey indicating a region that has age distribution of mortality composition equal to the Brazilian average (Kashnitsky and Schöley 2018). The results show that the spatial distribution is quite heterogeneous. Some meso-regions, for both males and females, in the South and Southeast, as well as in the state of Mato Grosso do Sul, have higher levels of mortality when compared to the Brazilian average in the age groups of 20-59 and 60+. On the other hand, in the central region of the country there are meso-regions with a higher mortality percentage in the 0-19 age group. Finally, we can also observe that many meso-regions in the North and Northeast (especially on the coast) have levels of mortality close to the Brazilian average.

The results depicted in the maps highlight the importance of looking at small areas. We can observe that results for meso-regions and states do not represent the differences observed within each area. For instance, in the state of Minas Gerais, the results indicate different patterns of mortality by age. The northern part of the state has a higher prevalence in adults (20-59) compared to the southern part, which has an older than the reference point. A similar pattern is observed in other areas, for males and females. 
Figure 2. Spatial distribution of deaths by Covid-19, age groups and sex in Brazilian mesoregions, 2020

Males

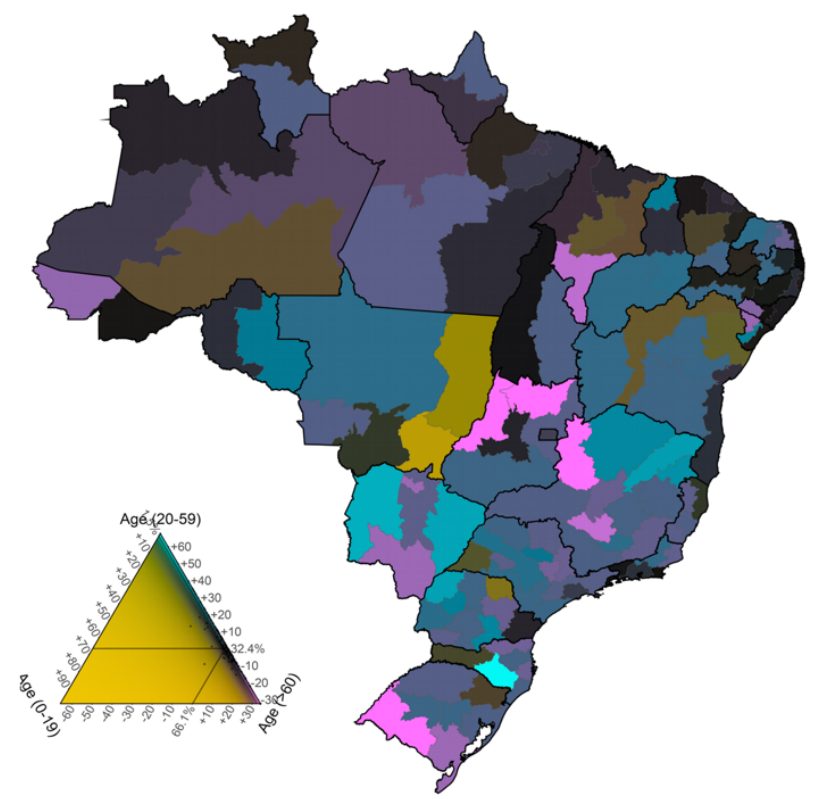

Females

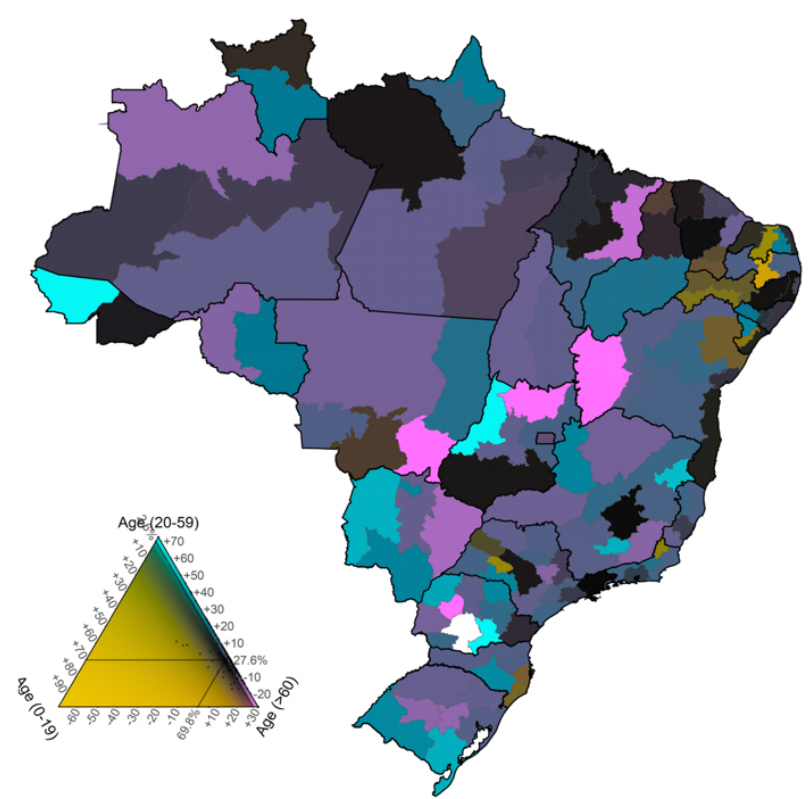

Source: Datasus (2020)

\section{Conclusion}

The results presented in this paper show that there are many pandemics going on in Brazil at the same time, instead of a single one. The pandemic is increasing in the interior of the country, but we still observed several cases and deaths in the major cities and, as of today, very few signs of reduction in the spread of the disease. We also show that the number of cases is more concentrated in females, but deaths are prevalent among men. The CFR for males is greater than the one for females, and mortality for young adult males is greater than it is in other countries (Natale et al. 2020). 


\section{References}

Anderson, R. M., Heesterbeek, H., Klinkenberg, D., \& Hollingsworth, T. D. (2020). How will country-based mitigation measures influence the course of the COVID-19 epidemic? Lancet (London, England), 395(10228), 931-934. https://doi.org/10.1016/S0140$6736(20) 30567-5$

Baptista, E. A., \& Queiroz, B. L. (2020). Age Patterns of Covid-19 and Severe Acute Respiratory Illness in Brazil. unpublished manuscript.

Baptista, E. A., \& Queiroz, B. L. (2019). The relation between cardiovascular mortality and development: Study for small areas in Brazil, 2001-2015. Demographic Research, 41(51), 1437-1452. https://doi.org/10.4054/DemRes.2019.41.51

Barreto, M. L., Barros, A. J. D. de, Carvalho, M. S., Codeço, C. T., Hallal, P. R. C., Medronho, R. de A., Struchiner, C. J., Victora, C. G., Werneck, G. L., Barreto, M. L., Barros, A. J. D. de, Carvalho, M. S., Codeço, C. T., Hallal, P. R. C., Medronho, R. de A., Struchiner, C. J., Victora, C. G., \& Werneck, G. L. (2020). O que é urgente e necessário para subsidiar as políticas de enfrentamento da pandemia de COVID-19 no Brasil? Revista Brasileira de Epidemiologia, 23. https://doi.org/10.1590/1980-549720200032

Borges, G. M. (2017). Health transition in Brazil: Regional variations and divergence/convergence in mortality. Cadernos de Saúde Pública, 33(8). https://doi.org/10.1590/0102$311 \times 00080316$

Codeço, C. T., Villela, D., Coelho, F., Bastos, L. S., Gomes, M. F. C., Cruz, O. G., Lana, R. M., Piontti, A. P. y, Vespignani, A., \& Davis, J. T. (2020). Estimativa de risco de espalhamento da COVID-19 no Brasil e o impacto no sistema de saúde e população por microrregião. https://www.arca.fiocruz.br/handle/icict/40509

Dong, E., Du, H., \& Gardner, L. (2020). An interactive web-based dashboard to track COVID-19 in real time. The Lancet. Infectious Diseases, 20(5), 533-534. https://doi.org/10.1016/S1473-3099(20)30120-1

Dowd, J. B., Andriano, L., Brazel, D. M., Rotondi, V., Block, P., Ding, X., Liu, Y., \& Mills, M. C. (2020). Demographic science aids in understanding the spread and fatality rates of 
COVID-19. Proceedings of the National Academy of Sciences, 117(18), 9696-9698. https://doi.org/10.1073/pnas.2004911117

Dudel, C. (n.d.). Monitoring trends and differences in COVID-19 case fatality rates using decomposition methods: Contributions of age structure and age-specific fatality. 17.

França, E. B., Passos, V. M. de A., Malta, D. C., Duncan, B. B., Ribeiro, A. L. P., Guimarães, M. D. C., Abreu, D. M. X., Vasconcelos, A. M. N., Carneiro, M., Teixeira, R., Camargos, P., Melo, A. P. S., Queiroz, B. L., Schmidt, M. I., Ishitani, L., Ladeira, R. M., Morais-Neto, O. L., Bustamante-Teixeira, M. T., Guerra, M. R., ... Naghavi, M. (2017). Cause-specific mortality for 249 causes in Brazil and states during 1990-2015: A systematic analysis for the global burden of disease study 2015. Population Health Metrics, 15(1), 39. https://doi.org/10.1186/s12963-017-0156-y

Goldstein, J., \& Lee, R. (2020). Demographic Perspectives on Mortality of Covid-19 and Other Epidemics (No. w27043; p. w27043). National Bureau of Economic Research. https://doi.org/10.3386/w27043

Guilmoto, C. Z. Z. (2020). COVID-19 death rates by age and sex and the resulting mortality vulnerability of countries and regions in the world. MedRxiv, 2020.05.17.20097410. https://doi.org/10.1101/2020.05.17.20097410

Jin, J.-M., Bai, P., He, W., Wu, F., Liu, X.-F., Han, D.-M., Liu, S., \& Yang, J.-K. (2020). Gender Differences in Patients With COVID-19: Focus on Severity and Mortality. Frontiers in Public Health, 8. https://doi.org/10.3389/fpubh.2020.00152

Jordan, R. E., Adab, P., \& Cheng, K. K. (2020). Covid-19: Risk factors for severe disease and death. $B M J, 368$. https://doi.org/10.1136/bmj.m1198

Kang, Y.-J. (undefined/ed). Mortality Rate of Infection With COVID-19 in Korea From the Perspective of Underlying Disease. Disaster Medicine and Public Health Preparedness, 1-3. https://doi.org/10.1017/dmp.2020.60

Kashnitsky, I. (2020). COVID-19 in unequally ageing European regions. https://doi.org/10.31219/osf.io/abx7s 
Kashnitsky, I., \& Aburto, J. M. (2019). Geofaceting: Aligning small multiples for regions in a spatially meaningful way. Demographic Research, 41, 477-490. JSTOR. https://doi.org/10.2307/26850657

Kashnitsky, I., \& Schöley, J. (2018). Regional population structures at a glance. The Lancet, 392(10143), 209-210. https://doi.org/10.1016/S0140-6736(18)31194-2

Lima, E. E. C. de, \& Queiroz, B. L. (2014). Evolution of the deaths registry system in Brazil: Associations with changes in the mortality profile, under-registration of death counts, and ill-defined causes of death. Cadernos de Saúde Pública, 30(8), 1721-1730. https://doi.org/10.1590/0102-311X00131113

Natale, A., Ghio, D., Tarchi, D., Goujon, A., \& Conte, A. (2020). COVID-19 Cases and Case Fatality Rate by age. (Knowledge for Policy,).

Nepomuceno, M. R., Acosta, E., Alburez-Gutierrez, D., Aburto, J. M., Gagnon, A., \& Turra, C. M. (2020). Besides population age structure, health and other demographic factors can contribute to understanding the COVID-19 burden. Proceedings of the National Academy of Sciences, 117(25), 13881-13883. https://doi.org/10.1073/pnas.2008760117

Queiroz, B. L., Freire, F. H. M. de A., Gonzaga, M. R., \& Lima, E. E. C. de. (2017). Completeness of death-count coverage and adult mortality (45q15) for Brazilian states from 1980 to 2010. Revista Brasileira de Epidemiologia, 20, 21-33. https://doi.org/10.1590/19805497201700050003

Rezende, L. F. M., Thome, B., Schveitzer, M. C., Souza-Júnior, P. R. B. de, Szwarcwald, C. L., Rezende, L. F. M., Thome, B., Schveitzer, M. C., Souza-Júnior, P. R. B. de, \& Szwarcwald, C. L. (2020). Adults at high-risk of severe coronavirus disease-2019 (Covid-19) in Brazil. Revista de Saúde Pública, 54. https://doi.org/10.11606/s1518-8787.2020054002596

Ribeiro, F., \& Leist, A. (2020). Who is going to pay the price of Covid-19? Reflections about an unequal Brazil. International Journal for Equity in Health, 19(1), 91. https://doi.org/10.1186/s12939-020-01207-2

Rodriguez-Morales, A. J., Gallego, V., Escalera-Antezana, J. P., Méndez, C. A., Zambrano, L. I., Franco-Paredes, C., Suárez, J. A., Rodriguez-Enciso, H. D., Balbin-Ramon, G. J., SavioLarriera, E., Risquez, A., \& Cimerman, S. (2020). COVID-19 in Latin America: The 
implications of the first confirmed case in Brazil. Travel Medicine and Infectious Disease. https://doi.org/10.1016/j.tmaid.2020.101613

Schmertmann, C. P., \& Gonzaga, M. R. (2018). Bayesian Estimation of Age-Specific Mortality and Life Expectancy for Small Areas With Defective Vital Records. Demography, 55(4), 1363-1388. https://doi.org/10.1007/s13524-018-0695-2

Schöley, J. (2019). The centered ternary balance scheme: A technique to visualize surfaces of unbalanced three-part compositions. PAA Anual Conference. https://portal.findresearcher.sdu.dk/en/publications/the-centered-ternary-balance-schemea-technique-to-visualize-surf

Shuchman, M. (2020). Low- and middle-income countries face up to COVID-19. Nature Medicine. https://doi.org/10.1038/d41591-020-00020-2

Souza, C. D. F. de, Paiva, J. P. S. de, Leal, T. C., Silva, L. F. da, Santos, L. G., Souza, C. D. F. de, Paiva, J. P. S. de, Leal, T. C., Silva, L. F. da, \& Santos, L. G. (2020). Spatiotemporal evolution of case fatality rates of COVID-19 in Brazil, 2020. Jornal Brasileiro de Pneumologia, 46(4). https://doi.org/10.36416/1806-3756/e20200208

The Lancet. (2020). COVID-19 in Brazil: “So what?" The Lancet, 395(10235), 1461. https://doi.org/10.1016/S0140-6736(20)31095-3 